Ege Tıp Dergisi / Ege Journal of Medicine 2021; 60 (4): 418-422

\title{
Millard-Gubler Sendromlu bir olguda şaşılık ve okuloplasti cerrahisi
}

Strabismus and oculoplastic surgery in a case with Millard-Gubler Syndrome

\author{
Derya Özkan Osman Bulut Ocak Hilal Zeynep Ceylan \\ Birsen Gökyiğit (D) Muhittin Taşkapılı (D) \\ Sağlık Bilimleri Üniversitesi İstanbul Beyoğlu Göz Eğitim ve Araştırma Hastanesi, İstanbul, Türkiye
}

\section{ÖZ}

Millard-Gubler Sendromu (MGS), 6. ve 7. kraniyal sinir periferik felcine eşlik eden vücut karşı tarafında hemiparezi ya da hemipleji ile seyreder. Etiyolojide yaşa göre değişkenlik görülmekle birlikte pons hasarı ön plandadır. Tedavi ve prognoz esas olarak etiyolojiye bağlıdır. Kliniğimize sağ gözde içe kayma şikayetiyle başvuran 18 yaşındaki erkek hastada Millard-Gubler Sendromu düşünülmüş, ancak etiyoloji belirlenememiştir. Hastaya şaşılık ve lagoftalmus nedeniyle operasyonlar uygulanmış, sonuç olarak ortofori sağlanmış ve lagoftalmus düzeltilmiştir. Hastalara nöroloji kliniğinin bilgisi dışında yapılacak cerrahi müdahalelerin, hastalığın oküler bulgularını maskeleyebileceği unutulmamalı, multidisipliner yaklaşımla, nörolojik rehabilitasyonu da içeren konservatif tedavi uygulanmalıdır.

Anahtar Sözcükler: Millard-Gubler Sendromu, 6. kraniyal sinir felci, 7. kraniyal sinir felci, şaşılık, lagoftalmus.

\begin{abstract}
Millard-Gubler Syndrome (MGS) progresses with contralateral hemiparesis or hemiplegia accompanying peripheral palsies of 6th and 7th cranial nerves. Although the etiology varies according to age, pons damage is prominent. Treatment and prognosis mainly depend on etiology. An 18-yearold male patient applied to our clinic with the complaint of crossing in the right eye, Millard-Gubler Syndrome was considered but the etiology could not determine. Operations were performed to the patient due to strabismus and lagophthalmos, as a result orthophoria was provided and lagophthalmos was corrected. It should be kept in mind that may mask ocular findings of the disease if surgical interventions to be performed on patients without the knowledge of the neurology clinic, with a multidisciplinary approach, conservative treatment, including neurological rehabilitation should be administered.
\end{abstract}

Keywords: Millard-Gubler Syndrome, 6. cranial nerve palsy, 7. cranial nerve palsy, strabismus, lagophthalmos.

\section{GíRiş}

Millard-Gubler Sendromu, 6. ve 7. kraniyal sinir periferik felcine eşlik eden, vücut karşı tarafında hemiparezi ya da hemipleji ile seyreden bir hastalıktır. Nadir görülen bu sendromda klinik olarak 6. kraniyal sinir felcine bağlı dışa bakış kısıtııı̆ı, 7. kraniyal sinir felcine bağlı lagoftalmus

Sorumlu yazar: Derya Özkan

Sağlık Bilimleri Üniversitesi İstanbul Beyoğlu Göz Eğitim ve

Araştırma Hastanesi, İstanbul, Türkiye

E-posta: deryaozkan512@gmail.com

Başvuru tarihi: 04.08.2020

Kabul tarihi: 02.04.2021 ve kontralateral kortikospinal yol tutulumuna bağlı olarak ekstremitelerde paralizi/pleji görülür. Etiyolojisinde pons hasarı ön plandadır. Pons hasarına yol açabilecek her türlü hastalık (iskemi, enfeksiyonlar, tümörler vb.) bu sendroma sebep olabilir (1). 
$\mathrm{Bu}$ olgu sunumunda, Millard-Gubler Sendromu tanısı alan olgumuzun klinik özelliklerini ve olguya uygulanan şaşılık ve lagoftalmus cerrahilerini sunmayı amaçladık. Hastanın yasal vasisinden tıbbi verilerinin yayınlanabileceğine ilişkin yazılı onam belgesi alınmıştır.

\section{OLGU}

Çocukluktan beri sağ gözde içe kayma şikâyetiyle hastanemizin şaşılık birimine başvuran 18 yaşındaki erkek hastanın ailesinden alınan anamnezde, 3-4 yaşlarındayken ateşli bir hastalık geçirdiği ve bu nedenle yoğun bakım servisinde süresini tam olarak hatırlayamamakla birlikte, uzun bir süre yattığı öğrenildi. Ebeveyni tarafından şikâyetlerinin o dönemde başladığı belirtildi.

Hastanın yapılan oftalmolojik muayenesinde her iki gözde en iyi düzeltilmiş görme keskinlikleri (EIDGK) $\quad 0,9$ desimaldi. Biyomikroskopik muayenede, sağ gözde inferiorda punktat tarzda korneal boyanma ve açıkta kalma keratopatisi mevcutken, sol gözün ön segmenti doğal olarak izlendi ve fundus muayenesinde iki gözde de herhangi bir patolojiye rastlanmadı. Preoperatif Krimsky testi ile primer pozisyonda yakında ortalama 25 prizma diyoptrisi (PD), uzakta ortalama 30 PD sağ ezotropya (ET) mevcuttu (Şekil-1A). Sağ gözde dışa bakışta -3 kısıtıılık saptanırken (Şekil-1B), diğer kadranlarda göz hareketleri serbestti (Şekil-1C-D). Worth 4 nokta testinde uzak ve yakında sağ gözde supresyon mevcuttu ve Titmus fly testi sonucunda olguda stereopsis bulunmamaktaydı. Yapılan Hess testi 6. sinir felciyle uyumlu bulundu. Aynı zamanda sağ tarafta periferik fasiyal paralizi saptandı. Bell fenomeni pozitif olan hastanın lagoftalmusu mevcuttu. Altıncı ve 7 . kraniyal sinir felci birlikteliği görülen hastanın öyküsünden özellikle alt ve üst ekstremitelerde güçsüzlük nedeniyle çocukluk çağından beri fizik tedavi aldığı öğrenildi. Bunun üzerine hastadan radyoloji ve nöroloji konsültasyonu istendi. Yapılan görüntüleme tetkikinde sağ pons ventral parçada hipointens alanlar saptandı. Nöroloji tarafından klinik ve radyolojik bulgular ışığında hastaya Millard-Gubler sendromu tanısı kondu, ancak etiyolojiyi saptamak için ileri tetkiklere gereksinim olduğu öğrenildi. Sağ lagoftalmus ve keratopati nedeniyle üst göz kapağı tarsına altın ağırlık uygulaması, sağ içe kayma nedeniyle ise çift taraflı medial rektus (MR) kası $5 \mathrm{~mm}$ geriletme cerrahisi planlandı. Genel anestezi altında olguya her yöne zorlu düksiyon yapıldı, sağ gözde -3 abdüksiyon kısıtııı̆ı mevcuttu. Her iki gözde konjonktiva, limbal insizyonla açılarak MR kaslarına ulaşıldı. Önceden belirlenen miktarda geriletme yapıldıktan sonra kaslar $6 / 0$ vikril sütür kullanılarak skleraya tutturuldu. Konjonktiva $8 / 0$ vikril sütür ile kapatıldı.

Olgunun postoperatif 1 . hafta muayenesinde her iki gözde EIDGK 0,9 desimaldi. Krimsky testi ile primer pozisyonda yakında ortoforken (Şekil-1E), uzakta ortalama 10 PD sağ ET mevcuttu. Sağ gözde dışa bakış kısıtlıı̆̆ı devam ediyordu, diğer kadranlarda göz hareketleri serbestti (Şekil-1F-G$\mathrm{H})$. Postoperatif 1 . ve 3 . ayda yapılan muayenelerde EIDGK seviyelerinde değişiklik saptanmadı. Sağ gözdeki dışa bakış kısıtlılığı devam ediyordu ve stereopsis yoktu. Postoperatif 3. ayda Krimsky testi ile primer pozisyonda yakında ortofori sağlanmış iken, uzakta ortalama 12 PD sağ ET mevcuttu. Anormal baş pozisyonu (ABP) bulunmuyordu.

Olgu okuloplasti birimine yönlendirildi. Şaşılık cerrahisinden 6 ay sonrasına altın ağırlık implantasyonu plandı. Operasyon öncesi kapağa yerleştirilecek ideal ağırlık, göz kapağı üzerine yapıştırılan deneme plakları ile değerlendirildi. Otuz dakikalık bir bekleme süresinden sonra kapak açıklığı ve her iki göz arasındaki simetri izlendi, uygun kalıcı implantın ağırlığına karar verildi. Supratarsal katlantı bölgesine cilt ve cilt altı insizyon yapıldıktan sonra orbikülaris okuli kas diseksiyonu ile tarsa ulaşıldı. Operasyon öncesi belirlenen altın implant, orbiküler kas ile tarsal tabaka arasında oluşturulan küçük cebin içine tars üzerinde uygun olan bölgeye $6 / 0$ prolen sütür ile tespit edildi. Orbikülaris okuli kası 6/0 vikril ET ve cilt $6 / 0$ prolen dikişlerle kapatıldı. Cilt dikişleri postoperatif 5. günde alındı. Hastanın açıkta kalma keratopatisinin gerilediği izlendi. 

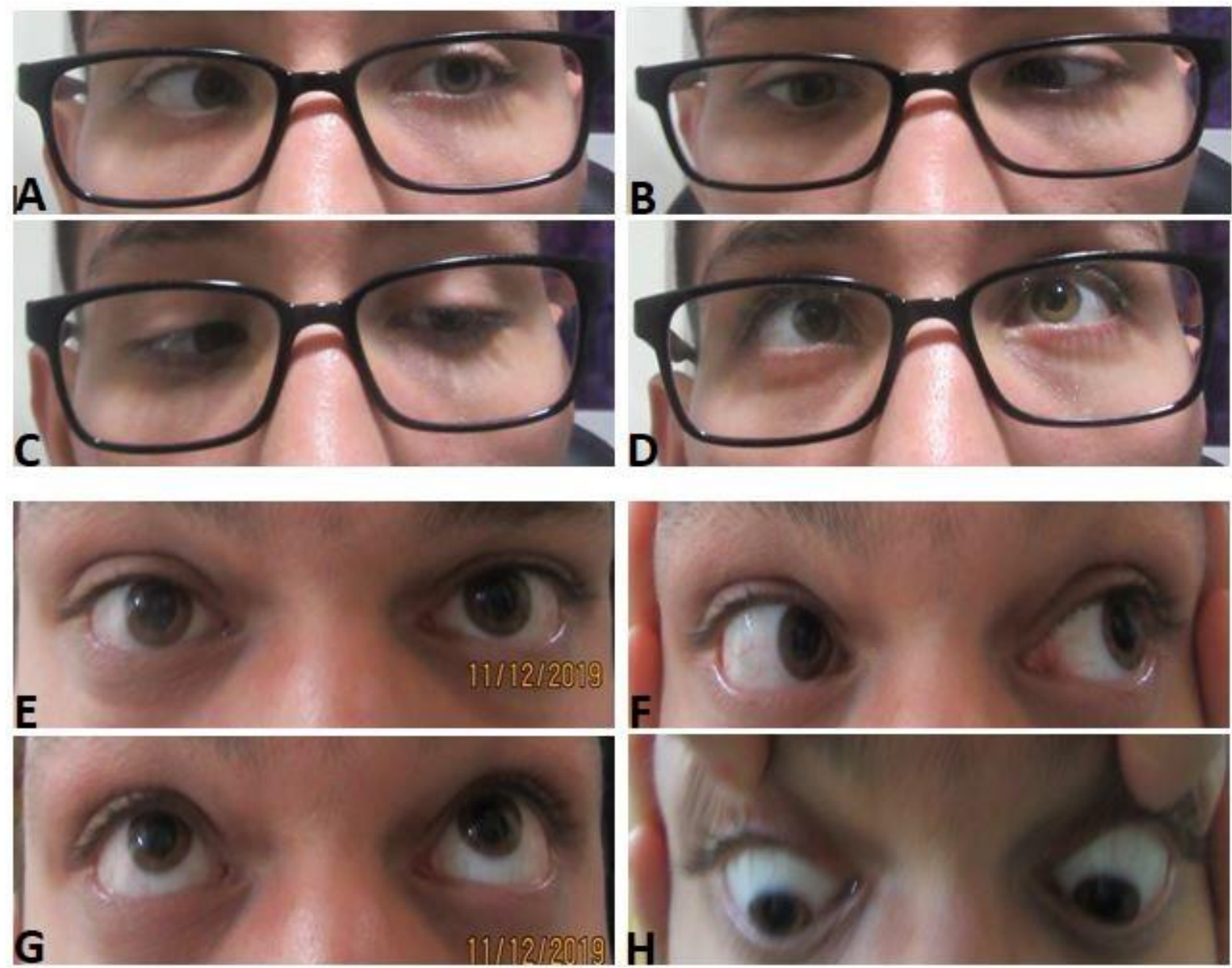

Şekil-1. Operasyon öncesi A) Primer pozisyonda sağ ezotropya B) Sağ gözde dışa bakış kısıtlılığı C-D) Diğer kadranlarda göz hareketleri serbest Operasyon sonrası E) Primer pozisyonda ortoforik F-G-H) Sola, yukarı ve aşağı bakışta göz hareketleri serbest.

\section{TARTIŞMA}

Fasiyal Abducens Hemipleji Sendromu ya da Ventral Pontin Sendrom olarak da bilinen MillardGubler

(9) etyolojili vaka takdimleri yapılmıştır Sendromu iki Fransız hekim tarafından tanımlanmıştır. Auguste Louis Jules Millard (1830-1915), 1855 yılında hastalığı ilk kez tanımlayan kişiyken, Adolphe Marie Gubler (1821-1879), bu olguyu bir yıl sonra bir tıp dergisinde yayınlamıştır (2). Ponsun ventromediyal bölümünü etkileyen lezyona bağlı gelişen sendromda, karşı kortikospinal yol lifleri, aynı taraf 6. kraniyal sinir lifleri ve 7. kraniyal sinirin fasiküler intrapontin parçası etkilenir. Buna bağlı olarak aynı tarafta dışa bakış kısıtıı̆ı̆ı, fasiyal paralizi, karşı taraf ekstremitelerde hemiparezi/hemipleji izlenir. Bu sendromda medial lemniskus ve spinotalamik yol tutulumu olmadığından duyu kaybı görülmez (3).
Etiyoloji yaşa göre değişkenlik gösterir. Literatür incelendiğinde, son $10 \mathrm{yıl}$ içinde tanı alan MillardGubler sendromlarına ait başvuru semptomları ve etiyolojik veriler Tablo-1'de gösterilmiştir. Genç yaşlarda, tümörler, enfeksiyöz ve demyelinizan hastalıklar daha sık görülürken; daha ileri yaşlarda hemoraji, iskemi, travma sonrası prepontin subaraknoid hematoma bağlı arter basısı gibi vasküler patolojiler daha ön plandadır (1). Literatürde günümüze kadar, 7 yaşında bir kız çocuğunda pontomedüller sistiserkoza bağlı enfeksiyöz (4), serebral infarkta bağlı iskemik (5, 6), kavernöz hemanjioma bağlı hemorajik (7), serebellopontin köşede hemanjioperisitoma ve kavernöz sinüs menenjiomuna bağlı tümöral (8) ve travmatik. Görüntüleme yöntemleriyle iskemik dört vakada vertebrobaziler sistemde oklüzyon saptanırken, iki vakada iskeminin sebebi net olarak ortaya konamamıştır. Bizim olgumuzda da görüntüleme ile pons hasarı tespit edilmiş olsa da sendroma neden olan patoloji açıklanamamıştır. 
Tablo-1. Son 10 yılda tanı alan Millard-Gubler Sendromları başvuru semptomları ve etiyolojileri.

\begin{tabular}{|c|c|c|c|}
\hline Bildiri yılı & Yaş / Cinsiyet & Başvuru anındaki semptomlar & Etiyoloji \\
\hline 2010 & 45 yaş erkek & $\begin{array}{l}\text { Horizontal diplopi, sol 7. kraniyal sinir } \\
\text { felci, sağ alt ve üst ekstremitede } \\
\text { güçsüzlük }\end{array}$ & $\begin{array}{l}\text { Sol pons akut enfarktı (+MDSA* } \\
\text { meningovasküliti) }\end{array}$ \\
\hline 2011 & 27 yaş kadın & $\begin{array}{l}\text { Sol periferik } 7 \text {. kraniyal sinir paralizi, } \\
\text { sağ hemipleji, diplopi }\end{array}$ & $\begin{array}{l}\text { Sol pons kavernöz hemanjiomuna bağlı } \\
\text { hemoraji }\end{array}$ \\
\hline 2012 & 7 yaş kadın & $\begin{array}{l}\text { Kusma, ağız kenarında sağa kayma, } \\
\text { 6. ve 7. kraniyal sinir felci, alt ve üst } \\
\text { ekstremitelerde güçsüzlük }\end{array}$ & Nörosistiserkoz \\
\hline 2013 & 63 yaş erkek & $\begin{array}{l}\text { Sol hemiparezi, sağ } 7 \text {. kraniyal sinir } \\
\text { felci }\end{array}$ & $\begin{array}{l}\text { Ventromedial medüller infarkt, baziller } \\
\text { sistemde diffüz aterosklerotik } \\
\text { değişiklikler }\end{array}$ \\
\hline 2016 & 42 yaş erkek & $\begin{array}{l}\text { Baş dönmesi, yürüme güçlüğü, sağ } \\
\text { periferik } 7 \text {. kraniyal sinir felci, } 6 \text {, } \\
\text { kraniyal sinir felci, sol hemiparezi }\end{array}$ & Primer meningeal hemanjioperisitom \\
\hline 2016 & 60 yaş kadın & $\begin{array}{l}\text { Sağ } 6 . \text { ve } 7 \text {. kraniyal sinir felci, sol } \\
\text { hemiparezi }\end{array}$ & Pons kavernöz anjiomu \\
\hline 2019 & 49 yaş erkek & $\begin{array}{l}\text { Baş dönmesi, bulantı, geveleyerek } \\
\text { konuşma, sağ } 7 \text {. kraniyal sinir felci, } \\
\text { sol hemiparezi }\end{array}$ & Vertebrobaziller arter disseksiyonu \\
\hline 2019 & 58 yaş kadın & $\begin{array}{l}\text { Akut vertigo, ani horizontal diplopi, } 7 . \\
\text { kraniyal sinir felci, kontralateral } \\
\text { hemiparezi }\end{array}$ & İzole pons enfarktı \\
\hline
\end{tabular}

*MDSA: Metisiline dirençli Staphylococcus aureus.

Bildirilen olguların hemen hepsinde başvuru anında ipsilateral fasiyal paralizi ve kontralateral ekstremite tutulumu gözlenirken, yalnızca bir kısmında göz hareketlerinde kısıtlılık, diplopi ve kayma saptanmıştır (1). Bizim vakamızda hastanın bize başvuru sebebi sağ gözde içe kaymaydı, diplopi tariflemiyordu. Sağ gözde abdüksiyon kısıtıılığı olan hastada 6 . kraniyal sinir felci mevcuttu. 6. kraniyal sinir felcinde lateral rektus kasının etkilenme derecesine göre cerrahi prosedür seçimi yapılabilir. Hafif dereceli parezilerde MR kası geriletmesi yeterli olurken, tam parezide abduksiyonu kuvvetlendirmek için geriletmeye vertikal transpozisyon eklenebilir (10). Biz, olgumuzda ABP olmadığı ve hasta abduksiyon kısıtılığından çok içe kaymadan şikâyetçi olduğu için MR geriletme yapmayı tercih ettik. Literatürde, MR kası geriletme cerrahisine ilaveten vertikal kas transpozisyonun da eklendiği kavernöz sinüs menenjiomuna bağlı bir MillardGubler Sendromu da bildirilmiştir. Ancak bu olgunun öncesinde diğer gözüne MR kası geriletme ve lateral rektus kası rezeksiyonu yapılmış olup hastada konsekütif ekzotropya ve anormal baş pozisyonu gelişmiştir (10).

\section{SONUÇ}

Tanı için detaylı bir hikaye ve fizik muayene gereklidir, klinik ya da radyolojik bulgular tanıda yardımcı olabilir (1). Tedavi ve prognoz esas olarak etiyolojiye bağlıdır (1). Nadir görülen bu sendromda; nörolojik bulguların atlanmaması ve tanı için multidisipliner yaklaşım gerekmektedir, nörolojik rehabilitasyonu da içeren konservatif tedavi önerilir (1). Özellikle oftalmolojik açıdan, yapılacak olası tüm şaşılık ve kapak cerrahileri, nöroloji kliniğinin bilgisi dahilinde olmalıdır. Nöroloji kliniğinin bilgisi dışında yapılacak cerrahi müdahaleler, hastalığın oküler bulgularını maskeleyebilir. Cerrahide esas amaç, içe kayma ve eğer varsa ABP'nin düzeltilmesi ve olası kornea hasarlarından korunmak için lagoftalmus cerrahileridir. Ekstraoküler kas ve kapak cerrahileri ile ortofori sağlanabilmekte ve lagoftalmus düzeltilebilmektedir.

Çıkar çatışması: Bu yayına ilişkin yazarların her hangi bir çıkar çatışması yoktur. 


\section{Kaynaklar}

1. Sakuru R, Elnahry AG, Bollu PC. Millard Gubler Syndrome. StatPearls [Internet] 2020 [cited 15 Jan 2020]. Available from: https://pubmed.ncbi.nlm.nih.gov/30422502/

2. Walusinski O. Adolphe Gubler (1821-1879) or Parisian neurology outside La Salpêtrière in the age of JeanMartin Charcot. Rev Neurol (Paris) 2019; 175 (4): 207-16.

3. Ceballos-Lizarraga R, Palomino-Díaz C, Romero-Figueroa JÁ. Wall-Eyed Monocular Internuclear Ophthalmoplegia (WEMINO) and Millard-Gubler Syndromes in a patient with isolated pontine infarction: Topographic, oculomotor, and radiological analysis of two very uncommon conditions. Case Rep Neurol 2019; 11 (2): 230-7.

4. Prasad R, Kapoor K, Srivastava A, Mishra O. Neurocysticercosis presenting as Millard Gubler syndrome. Journal of Neurosciences Rural Practice 2012; 3 (3): 375-7.

5. Rose DZ, Parra-Herran C, Petito CK, Post MJ. Restricted diffusion of pus in the subarachnoid space: MRSA meningo-vasculitis and progressive brainstem ischemic strokes - A case report. Case Reports in Neurology 2010; 2 (2): 101-10.

6. Li XT, Yuan JL, Hu WL. Vertebrobasilar artery dissection manifesting as Millard-Gubler Syndrome in a young ischemic stroke patient: A case report. World Journal of Clinical Cases 2019; 7 (1): 73-8.

7. Kesikburun S, Safaz I, Alaca R. Pontine cavernoma hemorrhage leading to Millard-Gubler Syndrome. American Journal of Physical Medicine \& Rehabilitation 2011; 90 (3): 263.

8. Ben Nsir A, Badri M, Kassar AZ, Hammouda KB, Jemel H. Hemangiopericytoma of the cerebellopontine angle: A wolf in sheep's clothing. Brain Tumor Research and Treatment 2016; 4 (1): 8-12.

9. Matsuyama T, Masuda A. A rare case of delayed traumatic Millard-Gubler Syndrome. No Shinkei Geka 1992; 20 (6): 697-9.

10. Dourado Leite R, Freitas C, Guimaraes S. Vertical muscle transposition with silicone band belting in VI nerve palsy. BMJ Case Rep 2016 doi: 10.1136/bcr-2016-216722 